\title{
ESTUDO DE CASO SOBRE O PLANO DE NEGÓCIO DA ASSOCIAÇÃO CULTURAL E EDUCACIONAL MADRE TERESA (ACEMT) SÃO JOSÉ DOS CAMPOS (SP)
}

\author{
Vinícius Paiva Prianti ${ }^{1}$ \\ Bruno Oliveira Matheus ${ }^{2}$ \\ Sergio Gurgel ${ }^{3}$ \\ Solange Batelli ${ }^{4}$
}

\begin{abstract}
Resumo Este trabalho é um estudo de caso sobre a Associação Cultural e Educacional Madre Teresa, localizada no município de São José dos Campos (SP), a fim de analisar e qualificar seu plano de negócio, identificar falhas através de divulgação, que dificulta a captação de recursos e voluntariados para a captação de recursos e voluntários. A partir disso, foi realizada uma pesquisa de campo aleatória e não estratificada, com 100 pessoas, no centro de São José dos Campos. Foi constatado que existe falha na divulgação e dificuldade de contribuidores para a associação. Segundo Kotler (2006, P.45) "um negócio pode ser definido em três dimensões; grupos de clientes, necessidades de clientes e tecnologia".
\end{abstract}

Palavras-chave: Plano de negócio; Associação; Voluntariado.

\footnotetext{
1 Administração/ Colégios Univap - Unidade Villa Branca, Brasil. E-mail: paivavinicius1@gmail.com.

2 Administração/ Colégios Univap - Unidade Villa Branca, Brasil. E-mail: Duladusmoda@hotmail.com.

3 Professor especialista /Colégios Univap - Unidade Villa Branca, Brasil. E-mail: gurgelpress@yahoo.com.br.

${ }^{4}$ Professora especialista coordenadora Colégios Univap - Unidade Villa Branca, Brasil. E-mail: sbatelli@univap.br.
} 